\title{
Will Intellectual Property Rights Policy Increase Foreign Direct Investment and Promote Technological Innovation?
}

\author{
Debao Hu, Zhengkai Liu (D), and Jing Zhao \\ International College, Renmin University of China, Beijing, China \\ Correspondence should be addressed to Zhengkai Liu; zkliu@ruc.edu.cn
}

Received 23 October 2020; Revised 14 December 2020; Accepted 8 January 2021; Published 27 January 2021

Academic Editor: Weijun Zhou

Copyright (C) 2021 Debao Hu et al. This is an open access article distributed under the Creative Commons Attribution License, which permits unrestricted use, distribution, and reproduction in any medium, provided the original work is properly cited.

In this paper, we discuss the effects of intellectual property rights (IPRs) on FDI and indigenous innovation and the overall effects of IPR on the Southern and Northern countries. Our model predicts that tighter IPR is good for FDI and indigenous innovation; however, the effects vary according to the initial resource endowment such as skill level and absorptive capacity. By a game theory model, we also find that tighter IPR benefits both sides if the innovation is the common knowledge to both players, and it improves indigenous innovation and welfare in a short term, but they will emerge in the long run. We also discuss the further direction to an empirical study. Finally, we make the following conclusion: IPR is part of business environment, and tighter IPR in progress is good for boosting welfare of both sides. It is time to build a better environment for IPR, but the cost of patent enforcement policy and the trade barrier must be taken into account.

\section{Introduction}

Over the past four decades, there has been a global trend toward stronger intellectual property rights (IPRs) protection, especially after the enforcement of the Agreement on TradeRelated Aspects of Intellectual Property Rights by the WTO. During Donald Trump's presidency, the IPR dispute between China and the US becomes more tough, which has external shock to trade and foreign direct investment to the two countries and more countries. It also pushes China to accelerate transition to have more input to $R \& D$ aimed to establish its indigenous innovation system. In the eyes of ordinary people, stronger IPR means better business environment, as the improvement of business environment, more foreign direct investment will be attracted by the better environment, so it may be a good thing. However, it also has another side of the coin. For the developing countries, stronger IPR protection means a higher learning cost, which may also cut down the supply chain with developed countries. What is the reality? Naturally, we have this question: does tighter IPR policy increase foreign direct investment and thus promote technological innovation of host country? The answer will give guidance to the policy-making of IPR protection in a country, and it will have insights into the comprehensive policy tools of FDI.

Vernon [1] originally pays attention to the product cycle which assigned a central role to foreign direct investment (FDI), and earlier literature mainly focused on effects of IPR on innovation and diffusion in the perspective of closed economy [2]. Afterwards, there are various attempts to build the model related to long-term effects of IPR on the product innovation, economic growth, and terms of trade in the international product cycles, but the conclusions of these studies are different, even are inverse. Helpman [3] finds that the effects of tighter IPR depended on the channel of production transfer crucially. Tighter IPR in South increased product innovation rate, production transfer, and relative wage if FDI is the channel of production transfer but has opposite effects if production is transferred through imitation. He made the conclusion that tighter IPR can be more broadly interpreted as any incentive given by FDI. However, imitation is exogenous in his model. Lai [4] builds a dynamic general equilibrium model of the international product cycle and allows the level of FDI in the South to respond endogenously to changes in the tightening of IPR protection in developed countries, and the conclusion is in conflict with 
Helpman [3]. Based on Lai [4], Branstetter et al. [5] develop an international product cycle model in which innovation, imitation, and FDI are all endogenous. They got similar results with Lai [4].

Glass and Saggi [6] provide a product cycle model in which innovation and FDI are all endogenous. They distinguish imitation that targets the products of developed firms from the products of Multinational Corporations (MNCs), by supposing the costs of imitating are lower than costs of indigenous innovation such as independent R\&D. They make the conclusion that tighter IPR protection keeps MNCs safer from imitation, but no for the Northern firms. Instead, they make the conclusion that, for the sake of imitation difficulty, it generates resource wasting and imitation disincentive effects which reduce both FDI and innovation. More resources absorbed in imitation leads to less FDI and thus reduced innovation. Apparently, their finds are converse with Lai 's [4].

Chen and Puttitanun [7] conducted a study of 64 Patent Examiner Data Systems (PEDs) from 1975 to 2000. They showed that innovations in the developing countries increase with increasing IPR protection. Glass and $\mathrm{Wu}$ [8] try to explore the underlying mechanism and theory about the effects of IPR protection on FDI and innovation. In their model, firms in developed countries carry on innovation to improve the quality of existing products and may shift production to developing countries through FDI later on. Firms in developing countries then imitate the products of MNCs. They conclude that the effects of IPR protection depend on innovation types. Tighter IPR encourage FDI and innovation when the innovation is based on variety, but when innovation is based on quality improvements, it has an opposite effect. Hence, tighter IPR, by reducing imitation, may shift innovation away from a higher quality improvement in existing products toward developing new products. The overall effects on innovation and FDI are vague.

Empirical methods are used in related topics gradually. Yang et al. [9] consider the relationship between IPRs and innovations of 42 countries over the period 1996-2007. It is found IPR protection remains a significantly positive influence on innovations for high-income countries, but it has no effect on fostering innovations for non-high-income countries. Ezzeddine and Hammami [10] estimate a nonlinear threshold model applied to panel data on 10 emerging countries for 1985-2015. The results revealed a significant influence of the threshold of the intellectual property rights on innovation. In other words, there is an inverse- $U$ relationship between the IPR and innovation. Latest papers talk about the related topic with a special perspective. For example, Dai et al. [11] discuss the stock market returns with new technical indicators, which were found beneficial to the IPR and had the implication of predictability of firm trend correlated.

These models are very suggestive and provide lots of valuable theoretic insights, but it is assumed that the efficiency of Southern labor in innovation is so much lower than that of Northern labor; in equilibrium, only Northern firms do innovate, which is contrary to the real case between
China and America. Meanwhile, increased intellectual property rights (IPRs) protection is occurred in the South, and the imitation cost from Northern countries is much higher than before.

In fact, while imitation is prominent in the Southern countries, empirical evidence shows considerable innovative activities by the Southern firms. It is particularly important to consider innovation by the Southern firms when considering FDI in newly industrialized countries or in relatively technologically advanced developing countries. In different contexts, the importance of innovation in the less developed countries is acknowledged (Muniagurria and Singh [12]). However, these works are empirical and policy analysis and lack theoretic study on Southern indigenous innovation.

Based on previous literature, we build an extended North-South product cycle model in which Northern innovation and FDI, imitation, and Southern indigenous innovation are all endogenous. We contribute to the literature by introducing the theme in three critical ways: firstly, we introduce Southern indigenous innovation based on existing endogenous literature (by Grossman and Helpman [13]; Aghion and Howitt [14]; Glass and Saggi [6]; Branstetter et al. [5]; and Glass and $\mathrm{Wu}$ [8]). We distinguish it from Northern innovation, which is similar to imitative innovation caused by a spillover effect (not illegal despite of some grey areas), and it creates the product with a higher quality and lower cost than MNCs may do. We differentiate it from imitation too, which is an illegal activity, and produce the product with a lower quality and lower cost than MNCs do $[15,16]$. Secondly, we introduce constraint of skilled labor and the indigenous innovation in the South. The Southern innovative and absorptive capacity depends on its resource base, including the availability of skilled labor and a suitable level of organizational know-how [3]. On the contrary, MNCs use the technologies developed in the North, which are skill-complementary and designed to be used by skilled labor $[9,10,17,18]$. Hence, Southern imitators, Southern indigenous innovators, and MNCs will compete with a higher profit, which generates strategic behaviors between the North and the South. Zhuang and Zou [18] use the similar framework, and they focus on the North-South intellectual property rights conflict related with market structure. Thirdly, we introduce game theory to discover the nature of innovation and to discuss the effects of tighter IPR on the strategic behavior between the North and the South.

The remainder of the paper is organized as follows. Section 2 presents an extended endogenous product cycle model to reveal how technology flows are accompanied by FDI. Section 3 investigates the effects of tighter IPR given supply constraint of skilled labor in developing countries. Section 4 has the game theory analysis. Section 5 has the discussion of how to have empirical study. Section 6 draws the conclusions.

\section{The Model}

There are two regions (North and South) in the world, and free trade is allowed. A Northern firm or a Southern firm 
develops a product by incurring an upfront innovation cost. It then earns the opportunity to make a stream of future profits. It is assumed that the efficiency of Southern labor in innovation is lower than that of Northern labor; in equilibrium, Northern firms do R\&D, and Southern firms do indigenous innovation. There is infinite patent life in the North and South, and the patent law enforcement is perfect in North but imperfect in South. Therefore, imitation only occurs in the South, not in the North. It is assumed that imitation cost is lower than innovation cost.

Labor is the only factor of production, and labor endowment in region $i$ is $L^{i}(i=N, S)$. We assume that one labor supplies one unit inelastic labor service. It is used for R\&D and production in North or for indigenous innovation, imitation, and production in South. We assume that MNCs need skilled labor. Skilled labor is abundant in North and is scarce in South. At any time, a number of differentiated products (denoted by $n$ ) have been developed by the North and the South. Each innovation takes the form of the introduction of a new differentiated product in the economy by a firm. In equilibrium, Northern firms will transfer production toward South through FDI, a process which is called "multinationalization". Since wage is lower in developing countries, firms in developed countries will stop production once the internationalization of the production has been finished.

2.1. Consumers. The specification of consumer utilities follows Grossman and Helpman [13]. Consumers choose from a continuum of products $j \in[0,1]$, assume preferences are identical in the two regions, and the representative consumer from country $i \in[N, S]$ has additively separable intertemporal preference given by choosing expenditure $E(\tau)$ to maximize lifetime utility at time $t$ :

$$
U=\int_{t}^{\infty} e^{-\rho(t-t)} \log u(\tau) \mathrm{d} \tau, \quad \rho>0,
$$

subject to intertemporal budget constraint

$$
\int_{t}^{\infty} e^{-r(t-t)} E(\tau) \mathrm{d} \tau=\int_{t}^{\infty} e^{-r(\tau-t)} I(\tau) \mathrm{d} \tau+A(t), \quad \forall t,
$$

where $\rho$ is the common subjective discount factor, $r$ is the nominal interest rate, $I(\tau)$ is the instantaneous income, and $A(t)$ is the current value of assets. The instantaneous utility $u(\tau)$ is defined by

$$
u=\left[\int_{0}^{1} x(j)^{\alpha} \mathrm{d} j\right]^{1 / \alpha},
$$

where $x(j)$ denotes the consumption of good $j$ and $n$ the number of goods available and $0<\alpha<1$.

Under the above assumptions, the consumer's optimization problem can be reduced to a two-stage problem, where the agent solves a dynamic optimization problem of allocating $E(t)$ overtime and then solves a static optimization problem of choosing the various $x(j)$ subject to a budget constraint of $E(t)$ at time $t$. Given expenditure $E$, the standard solution to the static optimization problem gives the following:

$$
x(j)=p(j)^{-\varepsilon} \frac{E}{P^{1-\varepsilon}},
$$

where $\varepsilon=1 /(1-\alpha)$ is the elasticity of substitution between any two goods and $\varepsilon>1 . p(j)$ denotes the price of good $j$ and $P$ a price index such that

$$
P=\left[\int_{0}^{1} p(j)^{1-\varepsilon} d(j)\right]^{1 /(1-\varepsilon)} .
$$

Solving the two-stage procedure, the optimal spending rule is given by $(\dot{E} / E)=r-\rho$. Aggregate expenditure of all consumers in country $i$, which satisfies $E(\tau)=E_{N}(\tau)+E_{S}(\tau)$, is

$$
E(\tau)=\int_{0}^{1}\left[\sum p(j) x_{i}(j)\right] \mathrm{d} j .
$$

Following Grossman and Helpman [13], if $E(t)$ is normalized by $E(t)=1$ for all $t$, then we have $r(t)=\rho$ in steady state.

2.2. Product Market. There are four types of firms: Northern firms $(N)$, Northern multinationals $(M)$, Southern imitators SM, and Southern indigenous innovator SI. Denote firms by $J, J=N, M, \mathrm{SM}$, SI. Northern firms can either produce in the North or in the South. A firm needs one unit labor force to produce a unit output in the North, whereas $\theta \geq 1$ units labor service per unit output are needed in the South, due to the costs of coordinating decisions over larger distances and operating in relatively unfamiliar environment, as well as Southern skilled labor premium, based on ownership advantages derived from technological assets and brands value $[17,19]$. The four types of firms interact as shown in Figure 1.

There are $n$ goods in the world at time $t$, and $n_{S}$ and $n_{N}$ are produced in the South and in the North, respectively. Therefore, $n=n_{S}+n_{N}$. Let $n_{S}=n_{\mathrm{SM}}+n_{\mathrm{SI}}+n_{M}, n_{\mathrm{SM}}$ are products imitated by Southern imitators, $n_{\mathrm{SI}}$ are products innovated by Southern indigenous innovators, and $n_{M}$ are products produced in the South by multinationals.

Given the demand function in (4), wage rates in the North and the South are denoted by $w^{N}$ and $w_{N} w_{S}$, respectively. It is easy to show that prices of Northern firms are mark-ups over their marginal costs caused by market power:

$$
\begin{aligned}
& p^{N}=\frac{w^{N}}{\alpha}, \\
& p^{M}=\frac{\theta w^{S}}{\alpha} .
\end{aligned}
$$

Southern imitators can only produce those goods that they have been imitated successfully, and a firm needs one unit labor force to produce a unit output. We assume that a Southern firm has imitation toward multinationals only. Actually, Northern firms can possibly have their products imitated, but the risk of imitation they face is lower than that 


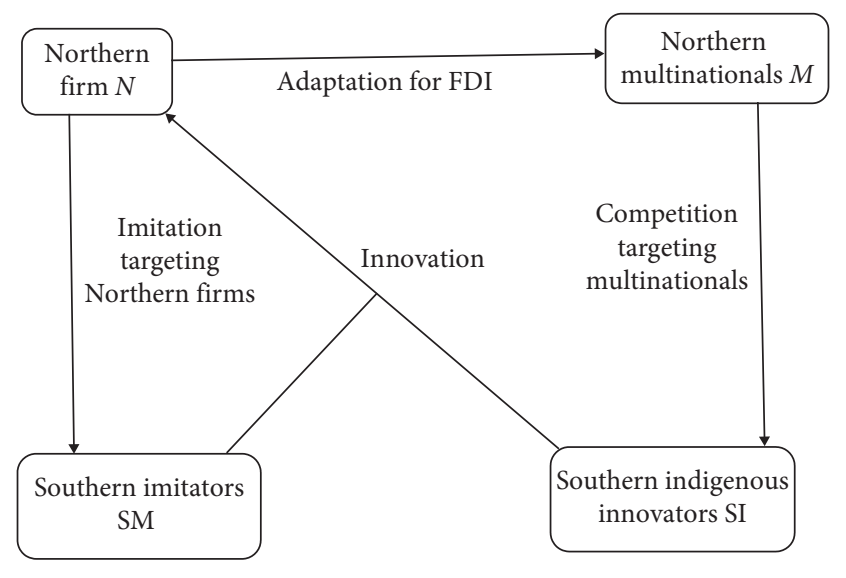

FIgURE 1: Four types of firm composition.

of multinationals [6]. A successful Southern imitator engages in price competition with the MNC and charges its optimal monopoly price:

$$
p^{S}=\theta w^{S}
$$

If Southern indigenous innovators get success, they will compete with MNCs by setting price. Similarly, we assume that indigenous innovation targets only MNCs. Actually, the price of Southern imitator can be held on when it lies below the marginal cost of multinational firm, which satisfies

$$
p^{\mathrm{SM}}=\frac{w^{S}}{\alpha} .
$$

We have $w^{\mathrm{SM}} / \alpha<\theta w^{\mathrm{SM}}, \theta \alpha>1$.

Meanwhile, Northern firms can possibly have their products innovated by Southern firms, but the cost is much bigger, and in equilibrium, we have

$$
p^{\mathrm{SI}}=\frac{w^{S}}{\alpha} .
$$

Obviously, we have $w^{S} / \alpha>w^{S} \theta, \theta \alpha<1$.

Let $x^{J}$ denote the output level of firm $x^{J}$, where $J=N, M, \mathrm{SM}$, SI. The variables $x^{N}, x^{\mathrm{SM}}, x^{\mathrm{SI}}$, and $x^{M}$ are determined by demand function (4) when the prices of the $n$ goods are known. From equation (4), we have

$$
\frac{x(i)}{x(j)}=\frac{p_{i}^{-\varepsilon}}{p_{j}^{-\varepsilon}}
$$

From (7), (8), and (10), we then have

$$
\begin{aligned}
& \frac{x^{\mathrm{SM}}}{x^{M}}=\alpha^{-\varepsilon}, \\
& \frac{x^{M}}{x^{N}}=\left[\frac{\theta w^{S}}{w^{N}}\right]^{-\varepsilon}, \\
& \frac{x^{\mathrm{SI}}}{x^{M}}=\theta^{\varepsilon} .
\end{aligned}
$$

Hence, the profit flows of a Northern firm, an MNC, a Southern imitator, and a Southern indigenous innovator are as follows:

$$
\begin{aligned}
& \pi^{N}=\left(p^{N}-w^{N}\right) x^{N}=\frac{(1-\alpha) w^{N} x^{N}}{\alpha}, \\
& \pi^{M}=\left(p^{M}-w^{S}\right) x^{M}=\frac{\theta(1-\alpha) w^{S} x^{M}}{\alpha}, \\
& \pi^{\mathrm{SM}}=\left(\theta w^{S}-w^{S}\right) x^{\mathrm{SM}}=(\theta-1) w^{S} x^{\mathrm{SM}}, \\
& \pi^{\mathrm{SI}}=\left(\frac{w^{S}}{\alpha-w^{S}}\right) x^{\mathrm{SI}}=\frac{(1-\alpha) w^{S} x^{\mathrm{SI}}}{\alpha} .
\end{aligned}
$$

2.3. Innovation and FDI. Innovation needs skilled labor. Skilled labor accumulation results in interaction between human capital and innovation of General Purpose Technology $[3,20,21]$ in developed countries. For simplicity, we assume sophisticated labor supply is increasing overtime:

$$
h_{N}=L^{N}-\left(1-s_{N}\right) L^{N} e^{-\beta_{N} t},
$$

where $s_{N}$ is the initial share of skilled labor in developed countries and parameter $\beta_{N}>0$ measures the rate of skill formation.

Following Grossman and Helpman [22], we assume the rate of invention per unit time $\dot{n}$ is given by

$$
\dot{n}=\frac{h_{N} K_{N}}{a_{N}},
$$

where $a_{N}$ is the parameter of innovation productivity, $h_{N}$ is the Northern skilled labor used in innovation, and $K_{N}$ is the accumulative knowledge stock used in innovation, where $K_{N}=n$, reflecting the spillover effect of past innovation on current innovation. We therefore define $g=\left(h_{N} / a_{N}\right)$.

In the North, labor is allocated to innovation and production:

$$
a_{N} g+n_{N} x^{N} \leq L^{N}
$$

The accumulation of skilled labor in the South results in interaction among Southern human capital investment, imitation, and FDI activities [23]. Similarly, we have

$$
h_{S}=L^{S}-\left(1-s\left(n_{s}\right)\right) L^{S} e^{-\beta_{S} t},
$$

where $s\left(n_{S}\right) \in(0,1)$ is the initial share of skilled labor in South and it is called cross-product skill transfer coefficient, which decreases with the increasing technical level of the product. Parameter $\beta_{S}>0$ measures the rate of skill formation.

We assume Southern indigenous innovators target MNCs' products only. Similarly, we define the rate of invention per unit time $\dot{n}_{\mathrm{SI}}$ is given by

$$
\dot{n}_{\mathrm{SI}}=\frac{h_{\mathrm{SI}} K_{S}}{a_{I}}
$$


where $a_{I}<a_{N}$ is the parameter of indigenous innovation productivity, $h_{\mathrm{SI}}$ is the Southern skilled labor used in innovation, and $K_{S}$ is the accumulative knowledge stock used in innovation, where $K_{S}=n_{S}$. We therefore define as follows:

$$
g_{S}=\frac{\dot{n}_{\mathrm{SI}}}{n_{M}}=\frac{n_{S} h_{\mathrm{SI}}}{n_{M} a_{I}} .
$$

Imitation is assumed to be costly, and the costs of imitation are averagely around 65\% of innovation costs [24]. We further assume imitation needs skilled labor. Given the scarcity of skilled labor in South, the rate of imitation per unit time $\dot{n}_{\mathrm{SM}}$ is given by

$$
\dot{n}_{\mathrm{SM}}=\frac{h_{\mathrm{SM}} K_{S}}{a_{M}},
$$

where $a_{M}<a_{I}$ is the parameter of imitation productivity, $h_{\mathrm{SM}}<h_{\mathrm{SI}}$ is the Southern skilled labor used in imitation, and $K_{S}$ is an accumulative stock of knowledge used in imitation, where $K_{S}=n_{S}$. Thus, the imitation rate $\mu$ is

$$
\mu=\frac{\dot{n}_{\mathrm{SM}}}{n_{M}}=\frac{n_{S} h_{\mathrm{SM}}}{n_{M} a_{M}} .
$$

MNCs use skill-biased technologies developed in the North, whose production is hence constrained by supply of skilled labor in South. We make distinction between two types of FDI and define the rate of horizontal FDI and the rate of vertical FDI as follows:

$$
\begin{aligned}
& \phi_{1}=\frac{n_{M} p^{M} x^{M}}{n_{S} p^{S} x^{S}}, \\
& \phi_{2}=\frac{\dot{n}_{M}}{n_{N}} .
\end{aligned}
$$

Accordingly, Southern resources constraints are

$$
\begin{gathered}
\frac{a_{I} \dot{n}_{\mathrm{SI}}}{n_{S}}+\frac{a_{M} \dot{n}_{\mathrm{SM}}}{n_{S}}+\theta n_{M} x^{M}+n_{\mathrm{SI}} x^{\mathrm{SI}}+n_{\mathrm{SM}} x^{\mathrm{SM}} \leq L^{S}, \\
h_{\mathrm{SI}}+h_{\mathrm{SM}}+h_{M} \leq h_{S},
\end{gathered}
$$

where $h_{M}$ is the Southern skilled labor used by MNCs. Southern labor is allocated to indigenous innovation, imitation, production of MNCs, and production of Southern firm. Southern skilled labor is therefore competitively used by MNCs, indigenous innovators, and imitators.

2.4. Steady State System. Following Helpman [3], Lai [4], and Branstetter et al. [5], we study a steady state equilibrium in which $r=\rho$ is satisfied, and all product categories grow at the same rate $g$. We thus have

$$
g_{N} \equiv \frac{\dot{n}}{n}=\frac{\dot{n}_{N}}{n_{N}}=\frac{\dot{n}_{\mathrm{SI}}}{n_{\mathrm{SI}}}=\frac{\dot{n}_{\mathrm{SM}}}{n_{\mathrm{SM}}}=\frac{\dot{n}_{M}}{n_{M}}=\frac{\dot{n}_{S}}{n_{S}} .
$$

Combining (21), (24), and (26), we have

$$
\begin{aligned}
\frac{n_{M}}{n_{N}} & =\frac{\phi_{2}}{g_{N}}, \\
\frac{n_{S}}{n_{N}} & =\frac{\phi_{2}\left(g_{N}+g_{S}+\mu\right)}{g_{N}^{2}}, \\
\frac{n_{\mathrm{SI}}}{n_{M}} & =\frac{g_{S}}{g_{N}}, \\
\frac{n_{\mathrm{SM}}}{n_{M}} & =\frac{\mu}{g_{N}}, \\
\frac{n}{n_{N}} & =1+\frac{\phi_{2}\left(g_{N}+g_{S}+\mu\right)}{g_{N}^{2}} .
\end{aligned}
$$

A successful innovator can produce either in the North or South. It is cheaper to produce in the South, while there is risk of imitation. The lifetime value of a successful innovator who chooses to produce in the North is

$$
v^{N}=\frac{\pi^{N}}{\left(\rho+g_{N}\right)} .
$$

If he chooses to be a MNC, its lifetime value is

$$
v^{M}=\frac{\pi^{M}}{\left(\rho+g_{N}+g_{S}+\mu\right)} .
$$

Because all Northern firms are free to become a MNC, we must have

$$
v^{N}=v^{M}
$$

Similarly, the lifetime value of a Southern imitator is

$$
v^{\mathrm{SM}}=\frac{\pi^{\mathrm{SM}}}{\left(\rho+g_{N}+g_{S}\right)} .
$$

The lifetime value of a Southern indigenous innovator is

$$
v^{S I}=\frac{\pi^{\text {SI }}}{\left(\rho+g_{N}+\mu\right)} .
$$

Because all Southern firms are free to imitation or indigenous innovation, we must have

$$
v^{\mathrm{SM}}=v^{\mathrm{SI}} \text {. }
$$

Freedom of innovation implies that the value of a Northern firm must be exactly the cost of innovation:

$$
v^{N}=\frac{w^{N} a_{N}}{n} \Longleftrightarrow \frac{\pi^{N}}{\left(\rho+g_{N}\right)}=\frac{w^{N} a_{N}}{n} .
$$

Freedom of indigenous innovation implies that the value of a Southern firm must be exactly the cost of innovation:

$$
v^{\text {SI }}=\frac{w^{S} a_{I}}{n_{S}} \Longleftrightarrow \frac{\pi^{\text {SI }}}{\left(\rho+g_{N}+\mu\right)}=\frac{w^{S} a_{I}}{n_{S}} .
$$

Similarly, freedom of imitation means 


$$
v^{\mathrm{SM}}=\frac{w^{S} a_{M}}{n_{S}} \Longleftrightarrow \frac{\pi^{\mathrm{SM}}}{\left(\rho+g_{N}+g_{S}\right)}=\frac{w^{S} a_{M}}{n_{S}} .
$$

We now examine North-South relative wage. Since $v^{N}=v^{M}$, we have

$$
\frac{\pi^{M}}{\pi^{N}}=1+\frac{\left(g_{S}+\mu\right)}{\left(\rho+g_{N}\right)}
$$

From the definition of profit, we also have

$$
\frac{\pi^{M}}{\pi^{N}}=\left[\frac{\theta w^{S}}{w^{N}}\right]^{1-\varepsilon}
$$

Combining (42) and (43), we have

$$
\frac{w^{N}}{w^{S}}=\theta\left[1+\frac{\left(g_{S}+\mu\right)}{\left(\rho+g_{N}\right)}\right]^{1 /(\varepsilon-1)} \text {. }
$$

In the steady state, from (21), (31), and (32), we have the equilibrium condition of labor market clearing in the North:

$$
a_{N} g_{N}+\frac{g_{N}^{2}}{g_{N}^{2}+\phi_{2}\left(g_{N}+g_{S}+\mu\right)} \frac{a_{N} \alpha\left(\rho+g_{N}\right)}{(1-\alpha)}=L^{N}
$$

In the steady state, from (28), (29), (31), and (32), we have the equilibrium condition of labor market clearing in the South:

$$
\begin{gathered}
g_{N}\left(a_{I} g_{S}+a_{M} \mu\right)+\frac{\theta a_{M} g_{N}\left(\rho+g_{N}+g_{S}\right)}{(\theta-1) \alpha^{-\varepsilon}}+\frac{\alpha a_{I} g_{S}\left(\rho+g_{N}+\mu\right)}{(1-\alpha)} \\
+\frac{a_{M} \mu\left(\rho+g_{N}+g_{S}\right)}{(\theta-1)}=L^{S}\left(g_{N}+g_{S}+\mu\right) \\
h_{\mathrm{SI}}+h_{\mathrm{SM}}+h_{M}=h_{S}
\end{gathered}
$$

Based on (13), (14), (31), (32), (39), and (40), we find the fourth equilibrium condition:

$$
\frac{\phi_{2}\left(g_{N}+g_{S}+\mu\right)}{g_{N}^{2}+\phi_{2}\left(g_{N}+g_{S}+\mu\right)} \frac{a_{N}\left(\rho+g_{N}\right)}{a_{I}\left(\rho+g_{N}+\mu\right)} \theta\left[1+\frac{\left(g_{S}+\mu\right)}{\left(\rho+g_{N}\right)}\right]^{\varepsilon /(\varepsilon-1)}=1 \text {. }
$$

Similarly, from (40), (41), (17), and (18), we find the fifth equilibrium condition:

$$
\frac{(1-\alpha) \theta^{\varepsilon} \alpha^{\varepsilon-1} a_{M}}{(\theta-1) a_{I}} \frac{\left(\rho+g_{N}+g_{S}\right)}{\left(\rho+g_{N}+\mu\right)}=1
$$

Equations (45)-(49) define the steady state equilibrium of the model in terms of five endogenous variables: the rate of Northern innovation, the rate of Southern indigenous innovation, the imitation rate, FDI, and the supply of skilled labor in South.

\section{The Effects of IPR Protection with Indigenous FDI}

To examine the effects of IPR protection, we use an increase in the cost of imitation $a_{M}(1+\kappa)$ or the cost of indigenous innovation $a_{I}(1+\kappa)$ as a measurement of the degree of IPR protection. A higher $\kappa \in[0, \infty]$ represents a higher degree of IPR protection.

Different from the assumption of exogenous initial imitation rate [3], this paper is to provide a product cycle model in which innovation, imitation, and FDI are endogenous. By equation (25), we will find that the rates of imitation depend on Southern skill levels $h_{S}$ and imitation productivity parameter $a_{M}$. Given $a_{M}$, initial rate of imitation is low when $h_{S}$ is low, and vice versa. Furthermore, indigenous innovation costs more skilled labor than that of imitation, and vertical FDI activities cost more skilled labor than that of horizontal FDI activities. This means the imitation rate not only depends on Southern skill level but also depends on the strategic behavior among imitators, indigenous innovators, and MNCs.

From (26), we have $\mu \in\left[0, h_{S} / a_{M}\right)$. Two cases deserve considering. (i) In the steady state, if skill level in developing countries satisfies $0<h_{S} \leq h_{S}^{c}$, then there exists a critical value of imitation rate $\mu_{c}$, and a low range of imitation rates $0<\mu<\min \left(\mu_{c}, h_{S} / a_{M}\right)$. (ii) If skill level in developing countries is so enough that $h_{S}>h^{c}$, and if $\mu_{c}<h_{S} / a_{M}$, there exists a high range of imitation rate $\mu_{c}<\mu<h_{S} / a_{M}$.

3.1. IPR Protection. Given weak IPR protection, will a Southern firm choose imitation or indigenous innovation? If the Southern firm chooses imitation, the successful imitator engages in Bertrand price competition with the MNCs whose product has been copied [22]. The question is now whether the Southern firm chooses indigenous innovation?

If a firm in developing country chooses and succeeds in indigenous innovation, given strategies of MNCs, it produces a product of higher quality and lower cost than MNCs can do. Because of free ride problem (all Southern firms can costless produce the indigenous innovated product), the economy will return to the steady state defined above. Given market demand of the product, price of the product will go down from $p^{M}=w^{\prime S} / \alpha$ to $p^{M}=w^{\prime S} / \alpha$. From (40), we can find that the expected return of the indigenous innovator deteriorates

$$
\frac{(\theta-1) w^{\prime S} x^{\mathrm{SM}}}{\left(\rho+g_{N}+\mu\right)}=\frac{w^{\prime S} a_{I}}{n_{S}}<\frac{w^{\prime S} a_{I}\left(1+h_{\mathrm{SI}}\right)}{n_{S}},
$$

where $w^{\prime S}>w^{S}$ representing skill premium and $h_{\mathrm{SI}}>0$ is the amount of skilled labor used in indigenous innovation. Obviously, the cost of indigenous innovator cannot be recovered, and thus, rational Southern firm always choose imitation under weak IPR protection. 
Proposition 1. Under weak IPR protection, there is no indigenous innovation, and imitation is Southern firm's dominant strategy.

If the South strengthens IPR protection, what happens to the strategies of Southern firm and MNCs? First, we discuss the effects of tighter IPR on imitation. We introduce IPR protection into (46), other things equal, let the rate of indigenous innovation be equal to zero, and we compute

$$
\frac{\partial \mu}{\partial \kappa}=\frac{\left[g_{N} \mu \theta+\theta g_{N} \alpha^{\varepsilon}\left(g_{N}+\rho\right)+\mu \rho\right]\left(g_{N}+\mu\right)}{(1+\kappa) g_{N}\left(\theta \alpha^{\varepsilon} \rho+\theta \alpha^{\varepsilon} g_{N}-\theta g_{N}-\rho\right)},
$$

where the value of numerator is positive. Sign of equation (51) depends on sign of $\delta=\theta \alpha^{\varepsilon} \rho+\theta \alpha^{\varepsilon} g_{N}-\theta g_{N}-\rho$. Obviously, the degree of market power (measured by $1 / \alpha[14]$ ) plays a crucial role here. We can find out a $\alpha^{*}=\left[\left(\rho+\theta g_{N}\right) /\right.$ $\left.\theta\left(\rho+g_{N}\right)\right]^{\varepsilon}, 0<\alpha<1$, satisfying $\delta=0$. Therefore, if $1 / \alpha<1 /$ $\alpha^{*}$, then $\delta>0, \partial \mu / \partial \kappa>0$; if $1 / \alpha>1 / \alpha^{*}$, then $\delta<0, \partial \mu / \partial \kappa<0$.
Thus, imitators' strategies depend on market structure. In the limit, we have

$$
\lim _{\kappa \longrightarrow \infty} \frac{\partial \mu}{\partial \kappa}=0
$$

Proposition 2. Under tighter IPR protection, imitators' strategies depend on the degree of market power. If $1 / \alpha<1 / \alpha^{*}$, then $\partial \mu / \partial \kappa>0$; if $1 / \alpha>1 / \alpha^{*}$, then $\partial \mu / \partial \kappa<0$.

Then, we discuss the effects of tighter IPR on indigenous innovation. Similarly, we introduce IPR protection into (46), other things equal, and we compute

$$
\frac{\partial g_{S}}{\partial \kappa}=\frac{\Delta\left(g_{N}+g_{S}+\mu\right)}{(1+\kappa) \Omega},
$$

where

$$
\begin{aligned}
& \Delta=g_{N}\left(a_{I} g_{S}+a_{M} \mu\right)+\frac{a_{M}\left(g_{N}+g_{S}+\rho\right)\left(\theta g_{N} \alpha^{\varepsilon}+\mu\right)}{\theta-1}+\frac{\alpha a_{I} g_{S}\left(\rho+g_{N}+\mu\right)}{1-\alpha}>0, \\
& \Omega=g_{N} a_{M} \mu-g_{N}^{2} a_{I}-g_{N} a_{I} \mu+\frac{a_{M}(\rho-\mu)\left(\left(\theta g_{N} \alpha^{\varepsilon}+\mu\right)\right.}{\theta-1}-\frac{\alpha a_{I}\left(\rho+g_{N}+\mu\right)\left(g_{N}+\mu\right)}{1-\alpha} .
\end{aligned}
$$

Obviously, the value of numerator is positive. Sign of equation (53) depends on sign of the denominator. In the limit, let $\mu=0$, then we have $\partial g_{S} / \partial \kappa>0$; i.e., if there is no imitation, tighter IPR will incentive indigenous innovation. If $\mu>0$ and $\mu \geq \rho$, we have $\partial g_{S} / \partial \kappa<0$. Thus, there will be a critical imitation rate, if IPR protection is not so tight. And beyond this critical value, imitation will retard indigenous innovation. Therefore, appropriate degree of IPR protection is a necessary condition of indigenous innovation; i.e., there exists a low bound $\underline{\kappa}>0$, satisfying equation (53), and $\partial g_{S} / \partial \kappa>0$. In the limit, we have

$$
\lim _{\kappa \rightarrow \infty} \frac{\partial g_{S}}{\partial \kappa}=0
$$

Obviously, we have $\underline{\kappa}<\kappa<\infty$.

Proposition 3. Appropriate degree of IPR protection is a necessary condition of indigenous innovation; i.e., there exists a low bound $\underline{\kappa}>0$, satisfying $\underline{\kappa}<\kappa<\infty$ and $\partial g_{S} / \partial \kappa>0$.

3.2. Foreign Direct Investment. The multinational firms are profit-oriented, so they are sensitive to the perceived strength of IPR protection. Such protections may induce foreign firms to produce and sell technologically advanced goods in the reforming southern country. Surveys of multinational managers suggest that technology transfer within multinational firm is sensitive to the perceived strengthening of IPR protection.

There are various reasons to suspect that the impact of IPR protection on FDI such as industry characteristics and hostcountry conditions is to be considered. The relevance of these factors can be derived from the OLI framework or "eclectic" paradigm, developed by Dunning [25, 26], according to which FDI is driven by the interplay between ownership, locations, and internalization motives. As industry characteristics, Maskus [27, 28] supposes that IPR protection is more important for FDI in industries with considerable intellectual property-related ownership advantages than for FDI in services, as well as in low-tech and standardized manufacturing. Likewise, host-country resource endowment conditions can be expected to shape the relationship between IPR protection and FDI. For example, the sensitivity of FDI to IPR protection is supposed to depend on the host countries' capacity for local imitation. On the one hand, IPR protection can be expected to induce more FDI in host countries with some imitative capacity. On the other hand, the effect of IPR protection on FDI may turn negative if imitative capacity goes hand in hand with particularly strong IPR protection, since licensing becomes more attractive.

FDI flows are the fraction of all product cycles occurred through imitation times the frequency of product cycles. Although the IPR is tighter, the rate of innovation increases, and a smaller fraction of international technology transfer will happen, which means the flows of FDI to developing countries will increase. In other words, it may harm the technology transfer, but the establishment of sophisticated market economy will make things better to increase FDI.

$$
\frac{\partial \phi}{\partial k}=\frac{\beta}{1-(w / \lambda)(1-\eta)} \frac{\partial \eta}{\partial k}=-\frac{\lambda}{w} \frac{\partial \beta}{\partial k}=\frac{\lambda}{w} \frac{\beta}{D}>0 .
$$

That is to say, FDI increases with a stronger IPR protection as well as technological innovation in developing 
country. FDI and imitation both serve as channels of international technology transfer although IPR protection crowds out some imitation activities, but it will optimize market competition environment, which will offset the decline accompanied by the imitation in host country. However, the business environment improvement will bring in more FDI, which will promote FDI finally. At the same time, when a firm transfers sensitive technology to a branch by FDI, usually it has to improve labor skills of local workers connected with key elements of its technology. Some of these elements may have been deliberately withheld from the firm's patents, but there is still a risk that the local employees will leave for another job to a local manufacturer, even taking sensitive technology with them to imitate. This is also accompanied by the process of spillover effect. By combining the patented and unpatented parts of technology, it will bring about the implication of these techniques. However, it will be trapped in the low-level imitation. That is to say, in a weak IPR environment, the multinational firms hardly have any restriction to the new parties. In the context of a stronger IPR environment with good patent protection, the firm can prevent the infringing firm from using the patented components of its technology. In addition, numerous patent reforms examined below explicitly included new protection of trade secrets or strengthened existing protection.

\section{Game Theory Analysis}

In a North-South framework, we build a two-period game theory model. For simplicity, suppose there is one firm in the North which targets becoming an international firm by FDI such as greenfield investment. In the first period, the Northern firm makes decision on how much R\&D expenditure is input. The expenditure depends on the net profit received by $R \& D$, which satisfies

$$
q(e) \cdot \pi_{2}+[1-q(e)] \pi_{1}-e,
$$

where $e$ is the $\mathrm{R} \& \mathrm{D}$ expenditure and $q(e)$ is the success probability of innovation, which is the common knowledge to both sides. The Northern firm will choose $e$ to make its payoff maximization. The first-order condition of the above formula is

$$
q^{\prime}(e)\left(\pi_{2}-\pi_{1}\right)=1
$$

Meanwhile, the Northern firm would choose to have the FDI for higher profit, which holds

$$
q(e) \cdot \pi_{2}+[1-q(e)] \cdot \pi_{1}-e>\pi_{1} .
$$

Because the Northern firm has a fixed cost $F$ in the first period, the total payoff of it will be $\pi_{1}-F$ in this period. And the payoff of the Northern firm in the two periods is

$$
\pi_{1}-F+q(e) \cdot \pi_{2}+[1-q(e)] \cdot \pi_{1}-e .
$$

Now the stronger IPR is introduced in the South. Suppose the IPR system is not perfect. We make the assumption that the Southern firm can imitate Northern firm technology without any cost in the first period, but the Southern local court has the possibility $\gamma$ to detect the behavior to have a penalty to the Southern firm. If not detected, it will continue to the imitation of the technology. So the reservation payoffs in the second period is either 0 or $(1-\gamma) \pi_{1}^{\prime}$. The intensity of FDI by the Northern firm depends on payoff got by it in the second period subgame. As soon as IRP is enforced, the Northern firm payoff is as follows:

$$
q(e) \cdot \pi_{2}+[1-q(e)] \cdot\left[\gamma \pi_{1}+(1-\gamma)\left(\pi_{1}-\pi_{1}^{\prime}\right)\right]-e .
$$

The first-order condition of the above formula is

$$
q^{\prime}(e) \cdot\left\{\pi_{2}-\left[\gamma \pi_{1}+(1-\gamma)\left(\pi_{1}-\pi_{1}^{\prime}\right)\right]\right\}=1 .
$$

In fact, $\gamma$ can be used as an index to measure the strength of IPR. The higher the $\gamma$ is, the stronger the IPR regime is.

We can find that the total payoff in two periods of Northern firm is a strictly concave function of the R\&D expenditure $e$, given the potential leading characters of the R\&D which satisfies the condition $q(e)$. Suppose $F=0$, and the total payoff is to maximize at the expenditure value of the following formula:

$$
\pi_{1}+q(e(\gamma)) \cdot \pi_{2}+[1-q(e(\gamma))] \cdot \pi_{1}-e(\gamma) .
$$

It is given by the condition

$$
q^{\prime}(e) \cdot\left(\pi_{2}-\pi_{1}\right)=1 .
$$

The condition (64) gives the level of R\&D investment, as well as condition (62) gives the actual R\&D investment in the subgame undertaken by the Northern firm. Suppose $\gamma=1$, and the two coincide. That is to say, the maximal payoff obtained by Northern firm is reached only when there is a strongest IPR regime and corresponds to the higher innovation rate (Figure 2). So the tighter IPR will increase innovation in the Southern sides as well as a greater payoff of Northern firm. This is why nearly worldwide countries and regions are making effort to improve their business environment. The optimal choice for the Southern government is to choose $\gamma=1$ in theory, but such a tighter IPR policy will crowd Southern firms out of imitation, which cannot offset the flow of FDI. So the progress in the policy should be dynamic and in pace to reach the ultimate goal.

\section{Empirical Study on IPR and Technological Innovation}

The multinational firms are profit-oriented, so they are sensitive to the perceived strength of IPR protection. Such protections may induce foreign firms to produce and sell technologically advanced goods in the reforming southern country. Surveys of multinational managers suggest that technology transfer within multinational firm is sensitive to the perceived strengthening of IPR protection.

When a firm transfers sensitive technology to an affiliate, it generally has to instruct local engineers and other local skilled workers concerning key elements of its technology. Some of these elements may have been deliberately withheld from the firm's patents, in the United States and in the foreign country, in order to prevent other parties from being 


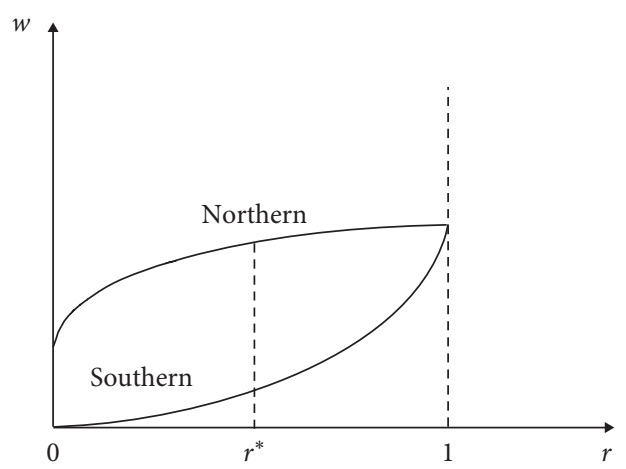

FIGURE 2: Welfare and IPR strength.

able to copy its technology simply by reading its patents. When it transfers this knowledge to local employee, there is a risk that these employees will defect to a local manufacturer, taking sensitive technology with them. These employees are able to combine the patented and unpatented elements of the firms' technology, effectively competing with it in the local market.

In a weak IPR environment, the multinational firm has little recourse. In the context of a stronger IPR environment with good patent protection, the firm can prevent the infringing firm from using the patented components of its technology. In addition, a number of the patent reforms examined below explicitly included new protection of trade secrets or strengthened existing protection.

Basic intuition suggests that if IPR regime shifts have a material impact on true intellectual property protection, then there should be an increase in the value of technology flows from parents to affiliate following regime changes. It is possible to test for this effect using regressions of the following form:

$$
\ln \mathrm{FDI}_{i t}=\sum_{c} \alpha_{c} \ln X_{i t}+\beta \ln \mathrm{IPR}_{i t}+\varepsilon_{i t},
$$

where $X$ are vectors of control variables, IPR is a measure of the strength of IPR, and $\varepsilon$ is an error term. Combining factors we are concerned with, the empirical specification is as follows:

$$
\ln \mathrm{FDI}_{i t}=\alpha_{1} \mathrm{GDP}_{i t}+\alpha_{2} \mathrm{OPEN}_{i t}+\alpha_{3} \mathrm{MANU}_{i t}++\beta \ln \mathrm{IPR}_{i t}+\varepsilon_{i t} .
$$

FDI denotes the FDI attracted by country $i$, and GDP represents the gross domestic product of country $i$, which reflects the economic development level of the country. OPEN means the openness of the country, which an essential part of business environment. MANU is the ratio of manufacturing factor to the GDP. As FDI is highly connected with manufacturing sector, it is adopted to measure the industry structure of the host country. IPR is used to measure the degree of intellectual property rights protection, which is the key variable. Most previous studies adopted the IPR index developed by Ginarte and Park [29], but the data were out of date. Yang et al. [9] used alternative indices surveyed by both IMD and WEF. The data can provide longitudinal and consistent measures of IPR strength by questionnaire, and a higher value corresponds to a stronger IPR protection. However, the indices of China are excluded. Meanwhile, the tighter IPR protection is underway mainly in these years. So it hard to have enough data. With the accumulation of the data and the solution of the measure tool, we can have further study on the correlation of IPR protection strength and FDI as well as technological innovation. It is the direction of our next research.

\section{Conclusion}

We build an extended North-South product cycle model in which innovation, imitation, and FDI are all endogenous. We extend existing models and contribute to the literature in three perspectives: first, we establish the skill accumulation function in the South and introduce constraint of skilled labor, and the imitation rate in the South is endogenous. Second, we take into account market structure and discuss the effects of tighter IPR in the framework of North-South's strategic action. Third, we have the welfare analysis with game theory.

It is found that, in the steady state, if the skill level is low and satisfies $\bar{h}_{S 1}<h_{S} \leq \bar{h}_{S 2}$, there exists a critical value of imitation rate $\mu_{c}$ with a low range of $0<\mu_{i}<\min \left(\mu_{c}, h_{S} / a_{I}\right)$. In oligopoly market with vertical innovation, tighter IPR protection hurts both regions. In monopolistic competition market with horizontal innovation, tighter IPR protection benefits both regions in the short run but hurts both in the long run. These conclusions are similar to those in Helpman [3], while the consideration of market structure makes a difference.

We further show that, in the steady state, when Southern skill level is high enough and satisfies $h_{S}>\mu_{c} a_{I}+\bar{h}_{S 2}$, and if $\mu_{c}<h_{S} / a_{I}$, there exists a high range of imitation rate $\mu_{c}<\mu_{i}<h_{S} / a_{I}$. In oligopoly market with vertical innovation, tighter IPR protection hurts both regions. In monopolistic competition market with horizontal innovation, we prove that there exists an optimal degree of IPR protection $\underline{\kappa}<\kappa^{*}<\bar{\kappa}$ in the South, which may differentiate from that in the North and also differ across Southern countries and industries. Under this optimal degree of IPR protection, tighter IPR protection can benefit both countries (regions).

Generally speaking, it is found that the effect of tighter IPR protection on FDI is positive, which is consistent with the substantial empirical results [30-37]. We developed a North-South quality-ladder model, in which foreign direct investment and imitation are the main channels of technology transfer. We then conducted not only a positive analysis but also a welfare analysis on intellectual property rights (IPR) protection in developing countries. We showed that strengthening IPR protection can raise welfare not only in developed countries but also in the developing countries. So it will increase the aggregate social welfare. The result is contrary with that of Helpman [3], whose pioneering study concludes that a stronger IPR protection in the South necessarily damages welfare in the South. However, our results differed markedly from Helpman's in this respect. Thus, our result provides a theoretical basis for strengthening patent protection in developing countries. To 
simplification, we abstracted from two factors whose incorporation would make the model more realistic. It also has insights into policy-making related to FDI and IPR protection. That is to say, when having policy decision, the following points much be taking into account.

Firstly, it is the cost of patent enforcement. In practice, resources are required to enforce IPR protection. For instance, the government must allocate sophisticated officials to institutions applying laws dealing with patent infringements. Hence, increasing IPR protection requires more regulation officials. Incorporating the costs associated with patent protection might result in our finding that strengthening patent protection improves developing country welfare being subject to more stringent restrictions.

Secondly, it is trade barriers between developed and developing countries. Trade barriers, in the form of tariffs, for example, are expected to affect both the benefits and costs of stronger patent protection in the South. For example, the existence of tariffs might induce tariff-jumping FDI from the developed country and might intensify the positive FDIpromoting welfare effect of strengthening patent protection. It is the reason why some American companies are still determining to move to developed countries including China under the background of trade policy during Trump Government's presidency.

\section{Data Availability}

This paper is for theoretical research with mathematical methodology, and no data were used to support this study.

\section{Conflicts of Interest}

The authors declare that they have no conflicts of interest.

\section{Acknowledgments}

This work was funded by the Pujiang Talents Plan (2019PJC097).

\section{References}

[1] R. Vernon, "International investment and international trade in the product cycle," The Quarterly Journal of Economics, vol. 80, no. 2, pp. 190-207, 1966.

[2] W. Siebeck, "Strengthening protection of intellectual property in developing countries: a survey of the literature," World Bank Discussion Papers, vol. 112, 1990.

[3] E. Helpman, "Innovation, imitation, and intellectual property rights," Econometrica, vol. 61, no. 6, pp. 1247-1280, 1993.

[4] E. L.-C. Lai, "International intellectual property rights protection and the rate of product innovation," Journal of Development Economics, vol. 55, no. 1, pp. 133-153, 1998.

[5] L. Branstetter, R. Fisman, C. F. Foley, and K. Saggi, Intellectual Property Rights, Imitation, and Foreign Direct Investment: Theory and Evidence, NBER Working Paper, no. w13033, Geneva, Switzerland, 2007.

[6] A. J. Glass and K. Saggi, "Intellectual property rights and foreign direct investment," Journal of International Economics, vol. 56, no. 2, pp. 387-410, 2002.
[7] Y. Chen and T. Puttitanun, "Intellectual property rights and innovation in developing countries," Journal of Development Economics, vol. 78, 2005.

[8] A. J. Glass and X. Wu, "Intellectual property rights and quality improvement," Journal of Development Economics, vol. 82, no. 2, pp. 393-415, 2007.

[9] C. H. Yang, Y. J. Huang, and H. Y. Lin, "Do stronger intellectual property rights induce more innovations? A cross-country analysis," Hitotsubashi Journal of Economics, vol. 55, no. 2, pp. 167-188, 2014.

[10] S. Ezzeddine and M. S. Hammami, "Nonlinear effects of intellectual property rights on technological innovation," Journal of Economic Integration, vol. 33, no. 2, pp. 1337-1362, 2018.

[11] Z. F. Dai, X. D. Dong, J. Kang, and L. Y. Hong, "Forecasting stock market returns: new technical indicators and two-step economic constraint method," North American Journal of Economics and Finance, vol. 53, pp. 101-116, 2020.

[12] M. E. Muniagurria and N. Singh, "Foreign technology, spillovers, and R \& D policy," International Economic Review, vol. 38, no. 2, pp. 405-430, 1997.

[13] G. M. Grossman and E. Helpman, "Endogenous product cycles," The Economic Journal, vol. 101, no. 408, pp. 1214-1229, 1991.

[14] P. Aghion and P. Howitt, "A model of growth through creative destruction," Econometria, vol. 60, no. 2, pp. 325-351, 1992.

[15] W. Lazonick and W. Mass, "Indigenous Innovation and Industrialization: Foundation of Japanese Development and Advantage," The MIT Japan Program, vol. 95, no. 3, 1995.

[16] W. Lazonick, "Indigenous innovation and economic development: lessons from China's leap into the information age," Industry \& Innovation, vol. 11, no. 4, pp. 273-297, 2004.

[17] D. Acemoglu and F. Zilibotti, "Productivity differences," The Quarterly Journal of Economics, vol. 116, no. 2, pp. 563-606, 2001.

[18] Z. Zhuang and W. Zou, "Market structure, FDI, imitation and innovation: a model of North-South intellectual property rights conflict," Journal of Chinese Economic and Business Studies, vol. 8, no. 3, pp. 253-267, 2010.

[19] J. R. Markusen, "Contracts, intellectual property rights, and multinational investment in developing countries," Journal of International Economics, vol. 53, no. 1, pp. 189-204, 2001.

[20] T. Bresnahan and M. Trajtenberg, "General Purpose technologies 'engines of growth'?” Journal of Econometrics, vol. 65, no. 1, pp. 415-426, 1995.

[21] P. Aghion, "Schumpeterian growth theory and the dynamics of income inequality," Econometrica, vol. 70, no. 3, pp. $855-882,2002$.

[22] G. M. Grossman and E. Helpman, "Quality ladders and product cycles," The Quarterly Journal of Economics, vol. 106, no. 2, pp. 557-586, 1991.

[23] S. L. Parente, "Technology adoption, learning-by-doing, and economic growth," Journal of Economic Theory, vol. 63, no. 2, pp. 346-369, 1994.

[24] E. Mansfield, M. Schwartz, and S. Wagner, "Imitation costs and patents: an empirical study," The Economic Journal, vol. 91, no. 364, pp. 907-918, 1981.

[25] J. H. Dunning, "Trade, location of economic activity and the mne: a search for an eclectic approach," in The International Allocation of Economic Activity, B. Ohlin, P. O. Hesselborn, and P. M. Wijkman, Eds., Macmillan, London, UK, 1977.

[26] J. H. Dunning, "Explaining the international direct investment position of countries: towards a dynamic or 
developmental approach," Weltwirtschaftliches Archives, vol. 117 , no. 1, pp. 30-64, 1981.

[27] K. E. Maskus, "The international regulation of intellectual property," Weltwirtschaftliches Archiv, vol. 134, no. 2, pp. 186-208, 1998.

[28] K. Maskus, Intellectual Property Rights in the Global Economy, Institute for International Economics, Washington, DC, USA, 2000.

[29] J. C. Ginarte and W. G. Park, "Determinants of patent rights: a cross-national study," Research Policy, vol. 26, no. 3, pp. 283-301, 1997.

[30] S. Lall, "Promoting technology development: the role of technology transfer and indigenous effort," Third World Quarterly, vol. 14, 1993.

[31] M. Bronckers, "The impact of TRIPS: intellectual property protection in developing countries," Common Market Law Review, vol. 31, pp. 1245-1281, 1994.

[32] P. McCalman, "Reaping what you sow: an empirical analysis of international patent harmonization," Journal of International Economics, vol. 55, no. 1, pp. 161-186, 2001.

[33] P. McCalman, "Foreign direct investment and intellectual property rights: evidence from Hollywood's global distribution of movies and videos," Journal of International Economics, vol. 62, no. 1, pp. 107-123, 2004.

[34] P. McCalman, "International diffusion and intellectual property rights: an empirical analysis," Journal of International Economics, vol. 67, no. 2, pp. 353-372, 2005.

[35] P. McCalman, "Who enjoys 'TRIPs' abroad? An empirical analysis of intellectual property rights in the Uruguay Round," Canadian Journal of Economics/Revue Canadienne d'Economique, vol. 38, no. 2, pp. 574-603, 2005.

[36] L. Branstetter, R. Fisman, C. F. Foley, and K. Saggi, "Does intellectual property rights reform spur industrial development?" Journal of International Economics, vol. 83, no. 1, pp. 27-36, 2011.

[37] E. Mueller, I. M. Cockburn, and M. MacGarvie, “Access to intellectual property for innovation: evidence on problems and coping strategies from German firms," Research Policy, vol. 42, no. 2, pp. 529-541, 2013. 